\title{
Janani Suraksha Yojana: Its utilization and perception among mothers and health care providers in a rural area of North India
}

\section{Vikas Kumar, Sunil Kumar Misra', Suneel Kumar Kaushal', Subhash Chand Gupta', Khan Amir Maroof}

Department of Community Medicine, University College of Medical Sciences, New Delhi,

${ }^{1}$ Department of Community Medicine, S.N. Medical College,

Agra, Uttar Pradesh, India

Address for the Correspondence: Dr. Vikas Kumar,

Department of Community Medicine, University College of Medical Sciences, Dilshad Garden, New Delhi - 110 095,

India.

E-mail: drvikaspsm@gmail.com

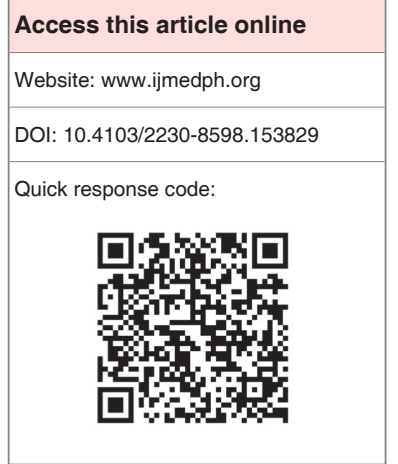

Background: Janani Suraksha Yojana (JSY) is a maternal protection scheme that promotes institutional delivery by providing cash incentive to the mothers who deliver their babies in a health facility. With the purpose of improving maternal and neo-natal mortality and morbidity indicators, the investment and emphasis on JSY is continued. Utilization pattern and perception in the community regarding a particular health program is important to study for assessing the success or failure of the program. Objectives: To assess the utilization of JSY and its perception among mothers and health care providers. Materials and Methods: A descriptive, crosssectional, community based study was Conducted at Agra district of Uttar Pradesh, among 246 married women of reproductive age group who had childbirth after JSY implementation for assessing their utilization pattern and perception regarding JSY services. Perception regarding the strengths and weaknesses of JSY among the health care providers was also studied. Results: Nearly half $(53.25 \%)$ of the mothers studied had an institutional delivery and were eligible for the JSY benefits. Postnatal home visits by Accredited Social Health Activists were done in $48 \%$ of home and $100 \%$ of institutional deliveries. Nearly half $(48.09 \%)$ of the beneficiaries were benefited by free transport facility under JSY. Although all of the health care providers perceived JSY as beneficial for improving maternal health, $44 \%$ of them had the notion that cash incentives under JSY can have a negative effect on family planning practices. Conclusion: The utilization rate of the JSY services was found to be low in certain aspects like institutional deliveries, transport facility etc., and there is scope for improvement.

Key words: Institutional delivery, Janani Suraksha Yojana, perception, utilization

\section{INTRODUCTION}

Global data show that maternal mortality ratio (MMR) ranges from 8/100,000 live births in developed countries to $500 / 100,000$ live births in developing regions. There is gradual improvement in the scenario in the previous year. ${ }^{[1]}$ In India, the MMR declined from about 520/100,000 live births in 1990 to nearly $254 / 100,000$ in 2004-2006 and to $212 / 100,000$ in 2007-2009. ${ }^{[2]}$ Despite this progress, the numbers of maternal deaths remained high, that is, 56,000 deaths in the year 2010, due to pregnancy related causes, the main cause of which is that a large number of deliveries are being conducted at home by untrained persons. ${ }^{[1]}$

"Janani Suraksha Yojana" (JSY) is the name in Hindi language that literally means "maternal protection scheme." JSY is an ambitious scheme launched in 2005 under the National Rural Health Mission, the Government of India's flagship health programme. The scheme is intervention for safe motherhood and seeks to reduce maternal and neo-natal mortality by promoting institutional delivery, that is, by providing a cash incentive to mothers who deliver their babies in a health facility. There is also provision for cost reimbursement for transport and incentives to Accredited Social Health Activists (ASHA) for encouraging mothers to go for institutional delivery. The scheme is fully sponsored by the Central Government and is implemented in all states and Union Territories, with special focus on low performing states like Uttar Pradesh. ${ }^{[3]}$ The importance of India to global maternal and neonatal health and the magnitude of the continued investment in JSY, draw attention to its utilization and 
perception among community as well as stake holders. The study was conducted with the objectives of assessing the utilization of services under JSY among mothers who had childbirth in the postimplementation phase of JSY and to know the perception regarding strengths and weaknesses of JSY among mothers and health care providers.

\section{MATERIALS AND METHODS}

This is a descriptive, cross-sectional, community based study conducted in ten randomly selected villages of a Sayian rural block of Agra district of Uttar Pradesh during July 2010 to June 2011. A minimum sample size of 203 was calculated by the formula, ${ }^{[4]}$ $n=4 \mathrm{pq} / \mathrm{d}^{2}$, based on the proportion (p) of institutional deliveries in Uttar Pradesh as $47 \%{ }^{\left[{ }^{[3]}\right.}$ and permissible error (d) as $15 \%$. All the women of the selected villages $(n=246)$ having at least one under five child which implied that she/he was born in the postimplementation phase of JSY were included in the study after obtaining an informed verbal consent for participating in the study. Pretested, structured schedule in local language, that is, Hindi was used for assessing the utilization pattern of JSY services, which included questions like place of delivery, postnatal visits by ASHAs and other services utilized under JSY during their last delivery. Study group women and health care providers were also interviewed about their perception regarding JSY. Women who had a still birth or abortion were excluded. Data were entered in Microsoft Office Excel 2007 (developed by Microsoft) and descriptive statistics such as proportions were computed.

\section{RESULTS}

The utilization rate of JSY scheme with regards to delivery at a public health facility was $53.25 \%$. Table 1 shows that out of these JSY beneficiaries $(n=131)$, nearly half $(48.09 \%)$ of these beneficiaries received a free transport facility, $79.39 \%$ were escorted by an ASHA and all of them received the cash incentive after delivery in the public health facility under JSY. Another interesting finding emerged that around $2 / 3^{\text {rd }}(65.65 \%)$ of the JSY beneficiaries had to spend some money at the public health facility for buying medicines and other consumables, while people expect to avail all the services free of cost.

Postnatal home visits by ASHAs were done at least once or more during $1^{\text {st }}$ week of delivery in $48 \%$ of home deliveries and $100 \%$ of institutional deliveries cases.

All the participant mothers were asked about their perception regarding benefits of JSY and each of them were allowed to tell single or multiple benefits. After compilation and analysis, frequency of each response was calculated. As depicted by Table 2 , about $2 / 3^{\text {rd }}$ $(65.85 \%)$ of them responded that cash incentive was benefit whereas $4.88 \%$ felt that there are no facilities in government hospitals, so JSY has no benefit for them. As shown in Table 3, we tried to assess the individual perception of various health care providers about weakness, strength and effect of JSY. They were asked about their experience at their respective workplace. When asked about the

\begin{tabular}{lc} 
Table 1: Utilization of the services under JSY \\
Particulars & $\boldsymbol{n}=131$ \\
\cline { 2 - 2 } & $\boldsymbol{n}(\%)$ \\
\hline Rent of vehicle paid by & \\
ASHA & $63(48.09)$ \\
Self & $68(51.91)$ \\
Escorted by ASHA & \\
Yes & $104(79.39)$ \\
No & $27(20.61)$ \\
Incentive received & \\
Yes & \\
Before discharge & $70(53.44)$ \\
Later & $61(46.56)$ \\
Total & $131(100.00)$ \\
No & $0(0.00)$ \\
Money spent by beneficiaries & \\
Nothing & $45(34.35)$ \\
<Rs. 200 & $6(4.58)$ \\
Rs. 200-<500 & $47(35.88)$ \\
$\geq$ Rs. 500 & $33(25.19)$ \\
\hline ASHA
\end{tabular}

ASHA = Accredited social health activists, JSY = Janani suraksha yojana

\begin{tabular}{lc} 
Table 2: Perception of the study group women \\
regarding benefits of JSY \\
\hline Perceived benefits ${ }^{* *}$ & $\boldsymbol{n}=\mathbf{2 4 6}$ \\
\cline { 2 - 2 } & $\boldsymbol{n}(\mathbf{\%})$ \\
\hline Don't know & $68(27.64)$ \\
Cash benefit & $162(65.85)$ \\
Safe delivery & $22(8.94)$ \\
Care of mother and baby & $39(15.85)$ \\
No facility in government hospitals & $12(4.88)$ \\
Free hospital delivery & $7(2.85)$ \\
Prevention and treatment of complications & $20(8.13)$ \\
No benefit of money as it spends in hospital & $3(1.22)$ \\
\hline$* *$ Multiple responses were allowed. JSY = Janani suraksha yojana
\end{tabular}

most important strength of JSY, most of them (89\%) said that "it ensures safe delivery by promoting institutional delivery." They were asked one most important weakness of JSY, their perception and suggestion about it. Almost half of them gave comments regarding cash incentive and suggested that it should be given only to poors and in first two deliveries and should be reasonably less than incentive after ligation otherwise it may have undesired effect on motivation of the couples seeking family planning. 33\% of them suggested that there should be availability of services of Gynaecologists for complicated deliveries at primary health center level either on part time basis or "on call services" basis. 11\% said that JSY lacks required emphasis on antenatal care to ensure better maternal health. They suggested that some cash incentive should be given at every antenatal check-up to ensure early and complete antenatal care.

Regarding effect of JSY on family planning practices, 44\% perceived that cash incentive has a negative effect on it by acting like a reward on giving birth to a child. According to them contraceptive use must have been decreased among poor and illiterate women. $67 \%$ of them said that JSY has a positive effect on immunization due to facility 


\begin{tabular}{|c|c|}
\hline Comments & Responders (\%) \\
\hline $\begin{array}{l}\text { Strength of JSY-ensure safe delivery by } \\
\text { promoting institutional delivery }\end{array}$ & 89 \\
\hline Better maternal and child care at health centre & 11 \\
\hline \multicolumn{2}{|l|}{ Weakness of JSY } \\
\hline Cash incentive is given to all including rich people & 11 \\
\hline Cash incentive is given in all deliveries & 22 \\
\hline Cash incentive is more in JSY than for ligation & 11 \\
\hline $\begin{array}{l}\text { Cash incentive is useless as it is spent at } \\
\text { home and not utilized by the beneficiary }\end{array}$ & 11 \\
\hline $\begin{array}{l}\text { No availability of services of Gynaecologists for } \\
\text { complicated deliveries at primary health centers }\end{array}$ & 34 \\
\hline $\begin{array}{l}\text { No provision of ensuring health of mothers } \\
\text { during antenatal period as it is of no use to } \\
\text { give incentive after delivery to a previously } \\
\text { malnourished-anemic mother }\end{array}$ & 11 \\
\hline \multicolumn{2}{|l|}{ Effect of JSY on } \\
\hline \multicolumn{2}{|l|}{ Delivery practices } \\
\hline Increased institutional deliveries & 100 \\
\hline \multicolumn{2}{|l|}{ Family planning practices } \\
\hline $\begin{array}{l}\text { Decreased in poor and illiterate/less } \\
\text { educated people }\end{array}$ & 44 \\
\hline No change & 44 \\
\hline Increased & 12 \\
\hline \multicolumn{2}{|l|}{ Immunization } \\
\hline No change & 33 \\
\hline Increased & 67 \\
\hline
\end{tabular}

JSY = Janani suraksha yojana

of giving BCG, OPV and hepatitis B birth dose before discharge of women from health center after institutional delivery.

\section{DISCUSSION}

In the present study, analysis of place of delivery reveals that delivery at government health facility was opted by $53.25 \%$. Malini et al. $(2008)^{[7]}$ in study in Orissa have reported comparatively higher number of institutional deliveries $(65 \%)$ which may be because the institutional deliveries reported by them includes government and private health facilities both, and also to the fact that the study was undertaken in a different region. Comparatively lower rate of institutional deliveries were reported by Singh D $(2002)^{[6]}$ in rural area of Ghaziabad (31\%), Iyengar et al. ${ }^{[8]}$ in a study in Rajasthan (34\%) and UNFPA study (2008) ${ }^{[3]}$ in U.P. (47\%) than present study. The difference can only be explained by difference in sociocultural background of the study area and time gap since a gradual rise in institutional deliveries has been observed since the inception of JSY.

In the present study in $79.39 \%$ JSY beneficiaries were escorted by ASHA and rent of vehicle was paid by ASHA to $48.09 \%$ beneficiaries. Malini et al. $(2007)^{[7]}$ in a study in Orissa also reported that in $78.3 \%$ cases ASHA escorted however comparatively less $(30.1 \%)$ beneficiaries received rent of vehicle. UNFPA study $(2008)^{[3]}$ and Uttekar et al. ${ }^{[5]}$ reported comparatively lower number of beneficiaries escorted by ASHA (15 and 38\% respectively) and number of cases in which rent of vehicle was paid by ASHA (19.2 and 29\% respectively). Reason may be explained on the basis that both the quoted studies were conducted 3 years back since then there has been continuous rise in institutional deliveries and awareness of the community regarding benefits of JSY; it may also be due to variation in availability of health services and level of motivation of ASHAs.

In our study all the beneficiaries $(100 \%)$ received cash incentive however comparatively less number of beneficiaries receiving cash incentive was reported by UNFPA study $(2008)^{[3]}$ in U.P. $(72.3 \%)$ and Malini et al. (2007) $)^{[7]}$ in Orissa (89\%). Uttekar et al. ${ }^{[5]}$ in their study reported that $51.2 \%$ beneficiaries received cash incentive after 1 -week of delivery which is more or less similar to present study. The variation may be attributed to awareness level of community related to JSY benefits.

A health worker female is supposed to do postnatal check-up, but it was found negligible in our study. This gap can be addressed to some extent by postnatal home visits by ASHAs. Although ASHAs cannot do postnatal check-up without training, but they are supposed to do home visits for counseling, assessment and referral. Present study reveals that postnatal visits at home by ASHAs were $100.00 \%$ in institutional deliveries and $48.00 \%$ in home deliveries. However Uttekar et al. ${ }^{[5]}$ in a study in U.P. has reported comparatively very low coverage $(11 \%)$ of postnatal Visit which again seems to be due to time gap. ASHAs thus are potential resource for reducing maternal and neonatal mortality after training in postnatal checkup in near future. Their availability and reach to community can be utilized for management and counseling of minor health problems and identification and referral in case of major health problems in postnatal period.

While assessing Awareness and Perception regarding JSY among study group women in our study, the most common response about benefits of JSY, was "cash benefit" in $65.85 \%$, followed by "don't know" in $27.64 \%$, "care of mother and baby" in $15.85 \%$, and "Safe delivery" in $8.94 \%$ women. Uttekar et al. ${ }^{[5]}$ have also reported similar findings. In their study facility of cash benefit was perceived a major benefit of JSY in $66.8 \%$ beneficiaries.

All of the health care providers perceived cash incentive as right policy for attracting, motivating and supporting the needy pregnant women. The similar perception was quoted by health workers in the qualitative study of Malini et al. (2007) ${ }^{[7]}$ in Orissa. In the present study the perception was that institutional deliveries have increased after implementation of JSY. Majority of them perceived that JSY has a negative effect on family planning practices. Few of them said that there is no provision of services of Gynaecologists for complicated deliveries in JSY. The similar perception was quoted by Medical Officers in the qualitative study of Malini et al. $(2007)^{[7]}$ in Orissa. They reported that inadequate number of doctors and staff in the health facility is one major problem as the increase in demand for institutional delivery on account of the JSY scheme is putting additional burden on rural health facilities and causing lack of quality services. 


\section{CONCLUSION}

Almost half of the women had delivery at a public health facility and utilized the benefits of JSY while few of the benefits of JSY were not reaching to all the beneficiaries like availability of free transport facility and free of cost delivery at government health facility as some money of beneficiaries was spent for purchasing of medicines etc. Majority of the mothers felt cash incentives as a strength whereas only few of them felt that poor facilities at public health facility were the weakness of JSY. Most of the health care providers perceived JSY a good scheme for promoting maternal and neonatal health except few lacunae which can be dealt with.

\section{Recommendations}

On the basis of the findings, few recommendations can be looked forward. Free and accessible transport facility should be stressed upon for better utilization of JSY. All the services at health facility should be provided free of cost to the JSY beneficiaries. Quality services at health facility should be assured as poor services is the reason for non utilization. Cash incentive should be given only in first two deliveries and should be reasonably less than the incentive after ligation and other family planning services acceptance.

\section{REFERENCES}

1. Park K. Park's Textbook of Preventive and Social Medicine. $22^{\text {nd }}$ ed. Jabalpur: Banarsidas Bhanot Publishers; 2013. p. 480, 518.

2. Sample Registration System. New Delhi: Office of Registrar General, India; 2011. Available from: http://www.censusindia.gov.in/vital_statistics/SRS_ Bulletins/MMR_release_070711.pdf. [Last accessed on 2014 Jul 10].

3. Concurrent Assessment of Janani Suraksha Yojana Scheme in Selected States of India. New Delhi: United Nations Population Fund; 2009. Available from: http://www.india.unfpa.org/drive/JSYConcurrentAssessment.pdf [Last accessed on 2011 Oct 17].

4. Suryakantha $\mathrm{AH}$. Community Medicine with Recent Advances. $2^{\text {nd }}$ ed. New Delhi: Jaypee Brothers Medical Publishers Ltd.; 2009. p. 646-7.

5. Uttekar BP, Uttekar V, Chakrawar BB, Sharma J, Shahane S. Assessment of Janani Suraksha Yojana in Uttar Pradesh. Vadodara: Centre for Operations Research and Training; 2008.

6. Singh D. A Study of Knowledge, Attitude and Practices Regarding Care of the Neonate in Rural Community. MD thesis, Faculty of Medical Sciences, University of Delhi; 2002.

7. Malini S, Tripathi RM, Khattar P, Nair KS, Tekhre YL, Dhar N, et al. A rapid appraisal on functioning of Janani Suraksha Yojana in South Orissa. Health Popul prospect Issues 2008;31:126-31.

8. lyengar SD, lyengar K, Gupta V. Maternal health: A case study of Rajasthan. J Health Popul Nutr 2009;27:271-92.

How to cite this article: Kumar V, Misra SK, Kaushal SK, Gupta SC, Maroof KA. Janani Suraksha Yojana: Its utilization and perception among mothers and health care providers in a rural area of North India. Int J Med Public Health 2015;5:165-8.

Source of Support: Nil, Conflict of Interest: None declared.

\section{New features on the journal's website}

\section{Optimized content for mobile and hand-held devices}

HTML pages have been optimized of mobile and other hand-held devices (such as iPad, Kindle, iPod) for faster browsing speed.

Click on [Mobile Full text] from Table of Contents page.

This is simple HTML version for faster download on mobiles (if viewed on desktop, it will be automatically redirected to full HTML version)

\section{E-Pub for hand-held devices}

EPUB is an open e-book standard recommended by The International Digital Publishing Forum which is designed for reflowable content i.e. the text display can be optimized for a particular display device.

Click on [EPub] from Table of Contents page.

There are various e-Pub readers such as for Windows: Digital Editions, OS X: Calibre/Bookworm, iPhone/iPod Touch/iPad: Stanza, and Linux: Calibre/Bookworm.

\section{E-Book for desktop}

One can also see the entire issue as printed here in a 'flip book' version on desktops.

Links are available from Current Issue as well as Archives pages.

Click on View as eBook 